\title{
Overhanging approximal restoration: clinical and radiography features at Tarogong Public Health Service, Indonesia
}

\author{
Anna Muryani*, Amaliya**, Devi Firena Garna**, Fahmi Oscandar***, Endang \\ Sukartini* \\ *Department of Conservative Dentistry, Faculty of Dentistry, Universitas Padjadjaran, Indonesia. \\ **Department of Periodontics Faculty of Dentistry, Universitas Padjadjaran, Indonesia. \\ ***Department of Dentomaxilofacial Radiology, Faculty of Dentistry, Universitas Padjadjaran, \\ Indonesia.
}

\begin{abstract}
Introduction: Overhanging approximal restoration may causes gingival inflammation, periodontal tissue destruction, decreases alveolar bone height, and caries recurrence. Overhanging restoration can be detected clinically and by radiography image. Overhang restorations can occur due to the poor filling procedures, one of which is the limitation of supporting tools. Restoration of teeth done in Public Health Center (Puskesmas) often found unavailability constraints supporting tools so that in cases of approximal caries often experience overhang. The aim of this study was to evaluate the incidence of overhanging proximal restoration at Tarogong Public Health Centre in Garut Regency, West Java, Indonesia. Methods: This study was a descriptive cross sectional for the incidence on patient with overhanging approximal restoration who visited at Dental Clinic Tarogong Public Health Center in Garut Regency. Intraoral clinical examination was conducted to examine visually and by tactile for the overhang restoration. Periapical radiography examination was taken and became supporting examination. Results: Collected data were 43 cases of overhanging approximal restoration from total 57 patients. The incidence of overhanging approximal restoration were $75.4 \%$. Conclusion: The conclusion of this study overhanging restoration approximal at Tarogong Public Health Centre in Garut Regency, West Java, Indonesia was $75.4 \%$.
\end{abstract}

Keywords: Overhang, approximal restoration, clinically features, radiography features

\section{INTRODUCTION}

The method presented by G.V. Black on caries classification since 100 years ago is still used in dentistry practice. According to GV Black Classification, Class II cavity ia a cavity that occur at the approximal surface of the posterior teeth which lies both at mesial and distal approximal surface, or either one. ${ }^{1}$
Restoration material is a material placed into the dental cavity after it is prepared. Restoration functions as dental tissue replacement for the tissues destroyed by caries process or other causes, to prevent the caries for relapsing, to maintain approximal space and contact point and to return occlusion, esthetic function and mastication. The restoration materials that are used for approximal cavity are amalgam, composite, or cast metal. ${ }^{2,3}$ 
The restoration procedure should be done carefully to avoid trauma and make the risk as minimum as possible. Restoration may stimulate plaque accumulation and each rough surface and overcontour will make it easier for plaque to be deposited despite cleaning efforts. Gingival irritation will increase if the restoration surface is rough or if there is a defect or overhang in the restoration (Fig.1). ${ }^{1-3}$

The imperfect restoration often causes mechanic stimulus in the form of iatrogenic irritant in the gingival tissue that is started by the presence of plaque retention area followed by gingival inflammation. Results from a research done by Jansson et al. and Padbury et al. It concludes that overhanging approximal restoration may cause periodontal diseases. ${ }^{4}$

The requirements that should be met in order to achieve good restoration include anatomical shape, maximum smoothness of the restoration surface, and good contact points. ${ }^{4}$ Caries is started from the part under the dental contact point. This concept suggests making dental restoration that matches the natural dental shape and contour. Restoration that is too big or restorations that do not match the natural dental shape and contour are referred as overhanging restoration. The restoration contour and anatomical shaping is referred as contoured filling which is aimed at reconstructing the approximal area, maintaining dental function, maintaining dental arch, preventing food impaction and maintaining the teeth so that they are healthy and comfortable to be used by the patient. This concept is aimed at reducing the occurrence of secondary caries. ${ }^{5}$

The data on health in West Java from Provincial Health Office showed that Garut District has $47.5 \%$ active caries presentation which was higher from the West Java presentation, i.e. 39\%.

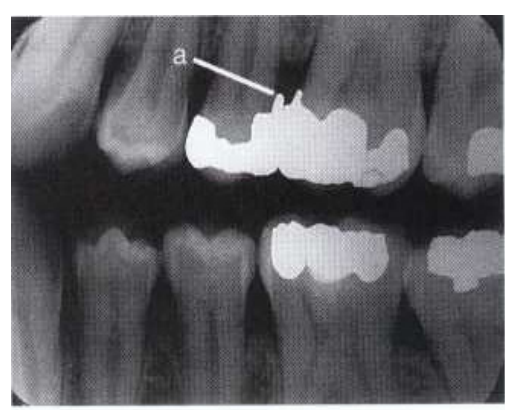

Figure 1. Radiograph of approximal filling with overhang. ${ }^{3}$
The same was also true for caries experience that $59.5 \%$, which was also higher than the percentage of the West Java Province percentage of $58.4 \%$. The DMF-T index of Garut District was $7.57 \%$ compared to $6.88 \%$ in the West Java Province. ${ }^{6}$ From the data it was apparent that the average dental decay number per individual in Garut district was higher than that of the individuals in West Java Province.

Most of Garut district population has bad habits, especially related to dental hygiene with $16.6 \%$ do not brush their teeth and $61.5 \%$ brush the teeth incorrectly and 63.2 percents have dental caries. In 2004, dental diseases was at the $7^{\text {th }}$ place of the top diseases in Tarogong Public Health Center area, as well as its patient visits on dental radiology facility for periapical radiograph had an average number of 30 patients a day. ${ }^{6}$ The ratio of dentist to 100,000 people in West Java was $1.6 \%$ in 2007. The health data in 2009 there was 18 dentists who serve 2,513,680 people in Garut District. From that data it can be concluded that the number of dentists, dental health facilities and infrastructures were not adequate yet to serve the population of West Java. ${ }^{6}$

This conditions will surely affect the quality of dental health services to the community, including teeth restoration service. The ideal approximal restoration will not be achieved if the dental health services inadequate due to limited supporting facilities and infrastructures. ${ }^{1,4,5}$

Based on the above background, the aim of this study was to observe into the incidence of overhanging at approximal restoration in patients who visited Tarogong Public Health Center, Garut District. The study about approximal restoration with overhanging are still very limited and has not been recorded systematically. This study results are expected to improve dental and oral health service quality that is needed by the people of Garut District.

\section{METHODS}

The method of this study was descriptive cross sectional. Sampling was conducted using purposive sampling that depends on time about 1 month. The samples were taken from patients with approximal restoration who had visited Tarogong Public Health Center, Garut District. Subjects included in this 
studies are both male and female outpatients, who have proximal restoration. Patients who have received proximal restorations less than 7 days are not included in the study.

Basic data on age, gender, occupation, smoking abit, home oral and dental hygiene measures, and dental visit frequency were collected for every sample involved in the study. Intraoral clinical examination was conducted and the dental status, where patients have dental filling and how long the filling had been there were recorded. The statistical analysis was conducted based on the incidence formula.

The overhanging approximal restoration is evaluated to see whether the restoration has restored the proximal morphology of the tooth bymeans of basic instruments and a radiograph. Evaluation of overhanging approximal restoration can be examined through visual, tactile, and radiographic parameters. Radiograph may be used as a tool to determine the overhanging restoration, given the radiopaque appearance resembles the restoration. Failure of reproducing proximal contour of the tooth as a result of overfilled material, and lack of embrasure space are considered as an overhanging proximal retoration clinically. Improper approximal restoration can be seen clinically through improper dental anatomical shape (Fig.2).

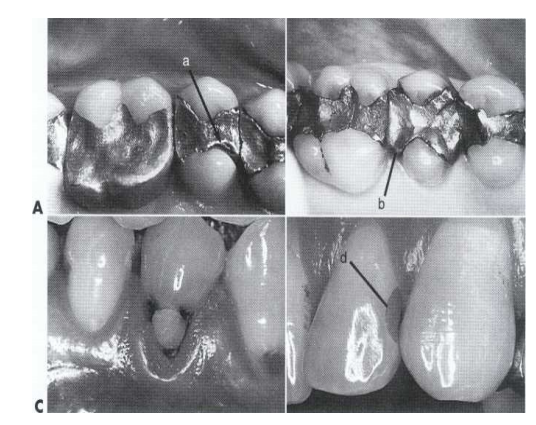

Figure 2. Improper approximal restoration

Table 1. Sample Distribution

\begin{tabular}{lc}
\hline Restoration condition & Number \\
\hline Approximal restoration cases & 57 \\
Overhanging approximal restoration cases & 43 \\
Non-overhanging approximal restoration cases & 14 \\
Total & 83 \\
\hline
\end{tabular}

\section{RESULT}

The number of patients receiving restoration were 83 and the total number of patients visiting the clinic were 254 . The approximal restoration being examined were 57 teeth, there were 43 with overhanging and 14 were non overhanging. The results about restoration condition among patients of Tarogong public Health Center, Garut District were shown in Table 1.

Based on the data in the table, the incidence of overhanging approximal restoration among patients in Puskesmas Tarogong, Garut District is calculated as $43: 57 \times 100 \%$ was $75.4 \%$.

\section{DISCUSSION}

A study done by Yasar et al..$^{7}$ stated that overhanging approximal restoration may cause gingival inflammation, periodontal tissue damage especially reduced alveolar bone height that may be caused by the easy plaque accumulation on the overhanging approximal restoration. Mjor et al. ${ }^{8}$ in their study stated that the overhanging approximal restoration is one of the causes of secondary recurrent caries as the bacterial entrance to the pulp that causes further infection in the pulp. ${ }^{7,8}$

Another study conducted at the dental clinic of Guilan University Hospital on overhang mentioned that the overall frequency of restoration overhang was $36.6 \%$, most of which was in class II amalgam restoration in the left first molar teeth in 30-39 year-olds. ${ }^{9}$ This was much different from the results of this study that found the incidence of overhang which is twice as much as reaching $75.4 \%$

In general, Tarogong Public Dental Health Service, Garut, Indonesia, does not have adequate facilities for ideal approximal restoration procedure and technique. For example, in general the approximal restoration does not use matrix and wedge during restoration and there is no polishing procedure after approximal restoration is finished which then leads to more overhanging approximal restorations compared to the non-overhanging one. When an overhanging approximal restoration is corrected that the restoration becomes nonoverhanging, gingival inflammation will be 
eliminated and alveolar bone support may improve leading to prevention of gingivitis, periodontitis, and recurrent caries. $^{7}$ A good restoration technique applied in approximal restoration will create non-overhanging approximal restoration. Restoration using matrix and wedge during filling and restoration material polishing will prevent overhanging approximal restoration. ${ }^{3}$ Based on the results of this study it can be suggested that it is necessary for Tarogong Public Health Centre, Garut, Indonesia to improve cooperation with government or related institution, in the effort to fulfill the facilities and infrastructure so as to improve the quality of health services especially in the field of dental conservation.

\section{CONCLUSION}

The conclusion of this study overhanging restoration approximal by clinical and radiography features at Tarogong Public Health Centre in Garut Regency, West Java, Indonesia was $75.4 \%$.

\section{REFERENCES}

1. Fisher J, Glick M. A new model for caries classification and management. J Am Dent
Assoc 2012;143(6):546-51. Available from: http: / /jada.ada.org June 2012 546-551.

2. Summit JBJ, Robbins R. Hilton TJ, Schwartz RS. Fundamental of operative dentistry. $3^{\text {rd }}$ ed. Chicago: Quintessence Book Inc.; 2006.

3. Roberson TM, Heymann HO, Swift Jr EJ. Sturdevant's art and science ofoperative dentistry. $5^{\text {th }}$ ed. St. Louis: Mosby. 2009.

4. Rajan K, Ramamurthy J. Effect of restorations on periodontal health. IOSR J Dent Med Scie (IOSR-JDMS) 2014:13(7):71-3.

5. Evans RW, Pakdaman A, Dennison PJ, Howe ELW. The caries management system: an evidence-based preventive strategy for dental practitioners, application for adults. Aust Dent J 2008;53:83-92.

6. Yasar F, Yesilova E, Akgunlu F. Alveolar bone changes under overhanging restoration. Clin Oral Invest 2009;14;543-9.

7. Mjor IA. Clinical diagnosis of recurrent caries. JADA 2005:136:1426-33.

8. Tavangar M, Darabi F, Tayefeh R, Davalloo, Saberi BV, Jahandideh $Y$, et al. The prevalence of restoration overhang in patients referred to the dental clinic of Guilan University of Medical Sciences. J Dentomaxillofac Radiol Pathol Surg 2016;5(1) 